\title{
Aspen Plus simulation of biomass gasification for different types of biomass
}

\author{
Ramesh Timsina Rajan K. Thapa Marianne S. Eikeland \\ Department of Process Energy and Environmental Technology University of South-Eastern Norway, \\ \{ramesh.timsina, rajan.k.thapa, marianne.eikeland\}@usn.no
}

\begin{abstract}
A steady-state Aspen Plus model was developed for biomass gasification in a fluidized bed reactor. A combination of different Aspen Plus unit operations was used to model the gasification process. The model was used to predict the gasifier performance for different operating conditions like temperature, Steam to Biomass Ratio (STBR) and biomass loadings. Further, the gas compositions were compared for different types of biomass feed. The gasification reactor is based on Gibbs minimization with restricted equilibrium approach. Hydrogen production was around $50 \%$ for all the biomasses while $\mathrm{CO}$ production varies from $8 \%$ (Pig manure) to $24.5 \%$ (Olive residue) at $700^{\circ} \mathrm{C} . \mathrm{H}_{2} / \mathrm{CO}$ ratio increases with an increase in STBR for all the biomass and the ratio was the highest for the pig manure and lowest for the olive residue. Olive residue, wood residue and miscanthus gave the $\mathrm{H}_{2} / \mathrm{CO}$ ratio of 1.5-2.1, which are more suitable as a feedstock in Fischer-Tropsch synthesis depending upon the operating temperature, a catalyst used and other operating conditions. For the wood residue, an increase in temperature increases the $\mathrm{H}_{2}$ and $\mathrm{CO}$ production whereas $\mathrm{CO}_{2}$ and $\mathrm{CH}_{4}$ concentration decreases and becomes stable after $700^{\circ} \mathrm{C} . \mathrm{H}_{2}$ concentration increased from $46 \%$ to 54 $\%$ and $\mathrm{CO}$ concentration decreases from $30 \%$ to $20 \%$ with an increase in STBR from 0.6 to 1 for the wood residue.
\end{abstract}

Keywords: Aspen plus, biomass, biomass gasification, $\mathrm{H}_{2} / \mathrm{CO}$ ratio

\section{Introduction}

Due to the increasing energy demand, and the rising global temperature, research is focused towards the alternative energy sources such as wind energy, solar energy and the energy from biomass. Biomass sources such as Municipal Solid Waste (MSW), food wastes, wood wastes, rice husks, sugarcane bagasse and poultry wastes can be utilized to produce product gases (a mixture of $\mathrm{CO}, \mathrm{H}_{2}$ and $\mathrm{CH}_{4}$ ) through biomass gasification. Biomass gasification is a thermochemical conversion of carbonaceous materials, mainly into syngas (a mixture of $\mathrm{CO}$ and $\mathrm{H}_{2}$ ), with the application of gasifying medium such as air, steam, and oxygen.
Among the different types of biomass gasification technologies, fluidized bed gasification is an attractive technology because of the even distribution of heat and mass transfer and excellent solid mixing. The fluidized bed gasification technology uses bed material to heat up the biomass particles in the temperature range of 700$900^{\circ} \mathrm{C}$ (Franco et al., 2003). The syngas can be converted into liquid fuels by Fischer-Tropsch (FT) synthesis, which is also known as Gas-To-Liquid (GTL) process (Riedel et al., 1999). Biomass gasification also enables energy recovery from the waste. The main challenge for the successful operation of the biomassbased energy production technologies is low carbon concentration in the biomass and the low efficiency of the biomass gasification technology.

The conversion of biomass into syngas gases through gasification especially depends upon the biomass characteristics. The amounts of the fixed carbon, volatiles, moisture, ash and the calorific value determines the output product gas composition (McKendry, 2002).

The biomass is dried and devolatilized during the gasification process. Devolatilization is an endothermic process where the hot bed material supplies the required amount of heat. For simplicity, the process of devolatilization can be modelled using 1 .

$$
\begin{aligned}
\mathrm{C}_{x} \mathrm{H}_{y} \mathrm{O}_{z}=a \mathrm{CH}_{4} & +b \mathrm{CO}+d \mathrm{CO}_{2}+e \mathrm{H}_{2} \\
& +f \mathrm{C}_{x} \mathrm{H}_{y}+g \mathrm{C}+h \mathrm{H}_{2} \mathrm{O}
\end{aligned}
$$

The amount of ash and the other minor components produced during the gasification process can be neglected. The conversion of biomass depends upon the pressure, temperature and heat and mass transfer. The next step is the char gasification. Char reacts with fluidizing agents, as well as $\mathrm{CO}_{2}$ and $\mathrm{H}_{2}$ produced during the devolatilization of the biomass. Char reactivity and its amounts affect the product gas compositions (Thapa and Halvorsen, 2014).

Figure 1 shows the potential reaction pathways for the biomass gasification process. Biomass undergoes pyrolysis to produces gases (such as $\mathrm{CO}, \mathrm{H}_{2}, \mathrm{CH}_{4}$, and $\mathrm{H}_{2} \mathrm{O}$ ), liquids (tar, oil), phenols, acids and the solid char. The char reacts with the gasifying medium, which 
further reacts with the gases produced during the pyrolysis process to give the product gas.

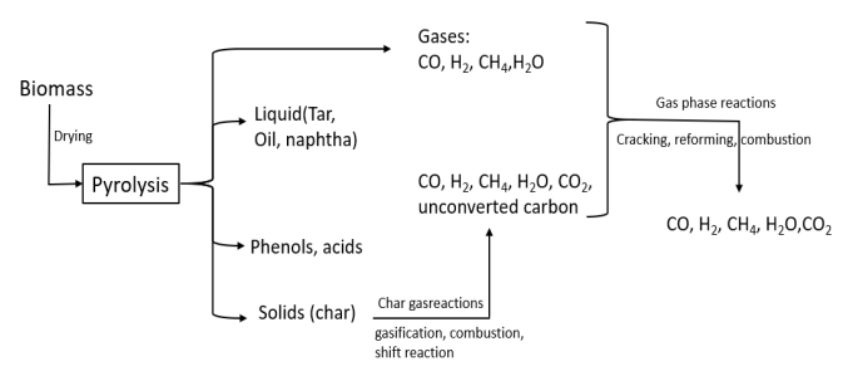

Figure 1. Potential reaction pathways for gasification

\subsection{1 Previous works}

Gagliano et al. have developed an equilibrium-based model in Aspen Plus for predicting the chemical composition of product gas for different types of biomass with different moisture contents. There is a good agreement of the gas compositions between simulation results and the experimental results for pellets and rubber wood (Gagliano et al., 2017).

Doherty et al. have developed a model which represents an industrial scale plant in Gussing Austria. The model is based on restricted equilibrium in RGibbs reactor and simulations were performed for various gasification temperature, moisture content of biomass, STBR, air-fuel ratio, air temperature and steam temperature. The simulation results for syngas compositions, cold gas efficiency and heating values agree well with the experimental data (Doherty et al., 2013).

Nikoo and Mahinpey simulated biomass gasification in a fluidized bed reactor. The model was validated with the experimental results from the lab-scale fluidized bed reactor. Effects of the different parameters such as temperature, equivalence ratio, STBR and biomass particle size were studied during their simulations (Nikoo and Mahinpey, 2008).

Liu et al. studied the simulation of biomass gasification based on the Gibbs equilibrium. The validated model was used to study the effects of gasification temperature, pressure and equivalence ratio. The optimal equivalence ratio was approximately 0.3 with optimal gasification efficiency of $85.92 \%$ (Liu et al., 2016).

Suwatthikul et al. have carried out the sensitivity analysis for gasification temperature, equivalence ratio and the STBR. A validated Aspen plus model gave an optimal operating temperature of $911^{\circ} \mathrm{C}$, equivalence ratio of 0.18 and STBR of 1.78 to achieve energy selfsufficient conditions for steam gasification in a fluidized bed reactor. Suwatthikul et al. achieved a maximum carbon conversion efficiency of $91.03 \%$ (Suwatthikul et al., 2017).

Product gases from the gasification process have to be cleaned further and adjusted accordingly for suitable application to the GTL process. Fuels from GTL process have low emissions of $\mathrm{CO}$, nitrogen oxides, hydrocarbons and particulate matters. The Fischer Tropsch synthesis can be considered as hydrogenation of $\mathrm{CO}$ to produce higher hydrocarbons compounds known as synthetic fuels (Kim et al., 2009). For the industrial application of syngas in Fischer-Tropsch synthesis, it is desired to have hydrogen to carbon monoxide ratio $\left(\mathrm{H}_{2} / \mathrm{CO}\right)$ of 1.5 - 2.1 (Tristantini et al., 2007).

Modelling and simulation of biomass gasification give a good understanding of the process, designing and optimization for a wide range of design configuration and operational parameters. The developed models can be used to study the biomass gasification process. Aspen Plus ${ }^{\circledR}$ is a commercial software package to simulate an industrial process. Although there is not included inbuilt library model to simulate fluidized bed biomass gasification in Aspen Plus, different unit operations

Table 1. Ultimate and Proximate analysis of different biomass feedstock

\begin{tabular}{|l|c|c|c|c|c|c|c|c|c|c|}
\hline \multirow{2}{*}{ Feedstocks } & \multirow{2}{*}{ Moisture } & \multicolumn{6}{|c|}{$\begin{array}{l}\text { Proximate analysis (wt. \%, } \\
\text { dry) }\end{array}$} & \multicolumn{6}{|c|}{ Ultimate analysis (wt. \%, dry) } \\
\cline { 3 - 14 } & $F C$ & $V M$ & $A s h$ & $C$ & $H$ & $O$ & $N$ & $S$ & $C l$ \\
\hline $\begin{array}{l}\text { Wood chips (Doherty et } \\
\text { al., 2013) }\end{array}$ & 20 & 18.84 & 80 & 1.16 & 51.19 & 6.08 & 41.3 & 0.2 & 0.02 & 0.05 \\
\hline $\begin{array}{l}\text { Wood residue (Fremaux et } \\
\text { al., 2015) }\end{array}$ & 5.01 & 17.83 & 81.81 & 0.36 & 50.26 & 6.72 & 42.66 & 0.16 & 0.2 & 0 \\
\hline $\begin{array}{l}\text { Pig manure (Xiao et al., } \\
\text { 2010) }\end{array}$ & 21.61 & 16.07 & 65.78 & 18.15 & 36.45 & 4.89 & 37.89 & 4.52 & 0.88 & 0 \\
\hline $\begin{array}{l}\text { Miscanthus (Kok and } \\
\text { Özgür 2013) }\end{array}$ & 2 & 16.33 & 82.14 & 1.53 & 45.52 & 5.93 & 48.32 & 0.13 & 0.1 & 0 \\
\hline $\begin{array}{l}\text { Olive residue (Masiá et al., } \\
\text { 2007) }\end{array}$ & 10.63 & 25.48 & 67.35 & 7.17 & 54.18 & 5.37 & 31.7 & 1.28 & 0.21 & 0.13 \\
\hline $\begin{array}{l}\text { Food waste(Begum et al., } \\
\text { 2013) }\end{array}$ & 29.3 & 20.69 & 72.4 & 6.91 & 56.65 & 8.76 & 23.54 & 3.95 & 0.19 & 0 \\
\hline
\end{tabular}


were combined to represent the biomass gasification as close as possible. This paper presents the simulation for different types of biomass presented in Table 1.

\section{Modeling of biomass gasification}

A model for bubbling fluidized bed biomass gasification with steam as a fluidizing agent is developed in Aspen Plus®. The model predicts the performance of a fluidized bed gasifier for the different types of biomass. The gasification process is dissociated into different representative units modelled by the different blocks in Aspen Plus. These models offer a convenient way to give information about the gasifier in a short time. These models are either based on kinetics rates or the state of thermodynamic equilibrium in a Gibbs reactor. The developed model is based on the restricted equilibrium in a Gibbs reactor model. Aspen plus flowsheet of the reactor is presented in Figure 2.

The flowsheet was developed from the available unit and non-conventional solids were present in the model with particle size distribution. Peng-Robinson equation of state with Boston-Mathias (PR-BM) alpha function was used to calculate the thermodynamic properties. Applications of PR-BM includes refineries, gasprocessing, and petrochemical applications like crude oil conversion and gas plants. All the inputs to the feed (flow rate, composition, thermodynamic state) and the unit operation block (thermodynamic conditions, chemical reaction etc) were taken from the experimental study performed by Fremaux et. al. (Fremaux et al., 2015). The assumptions made during the modelling of the gasification process in Aspen Plus are as follows:

- Isothermal and Steady state process.

- The pressure drop across the block is zero.

- Tar formation is not considered.

- The system is in steady state and isothermal.

- Char contains only carbon.

- Modelling of ash is not considered

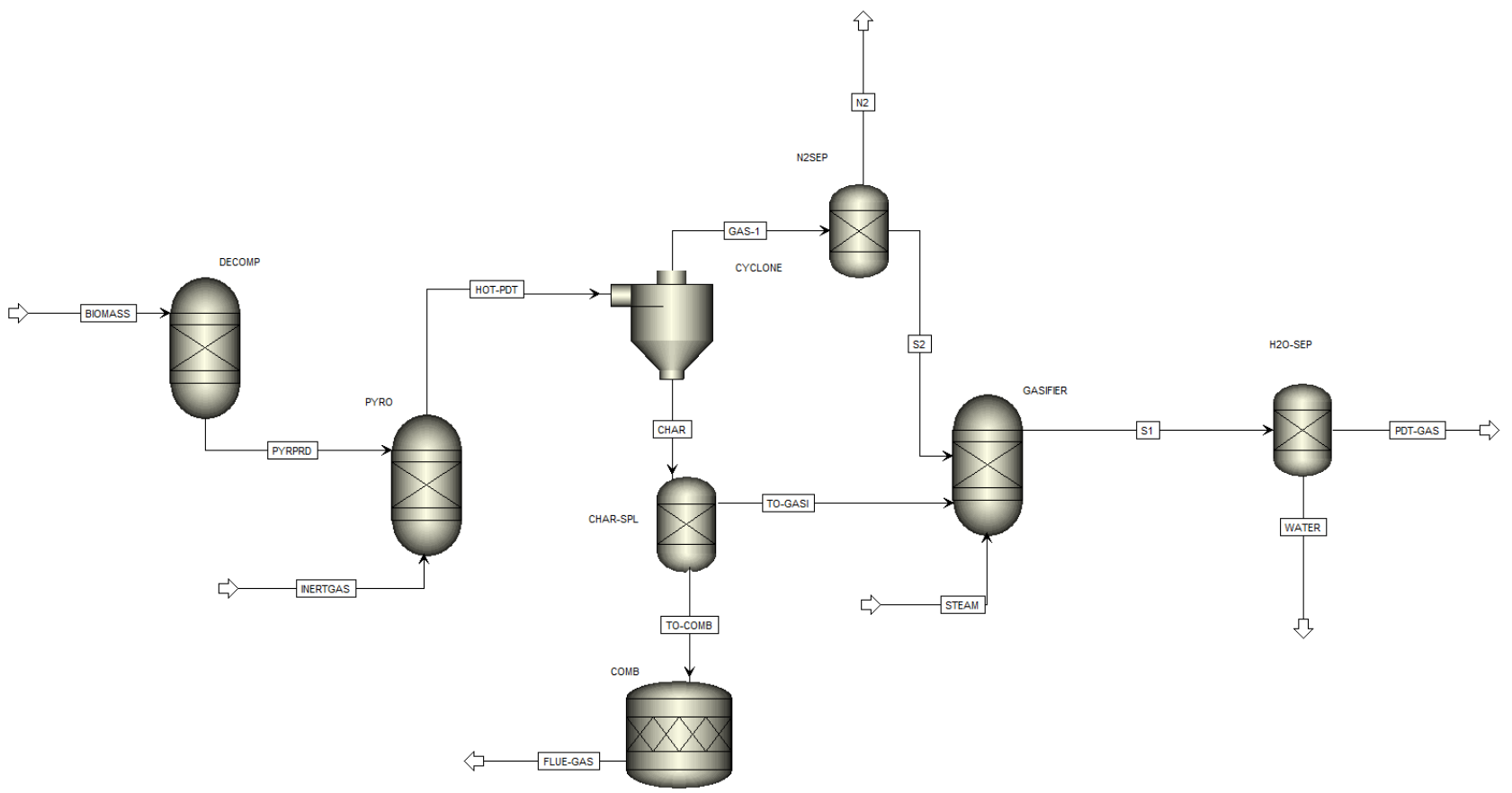

Figure 2. Aspen plus flowsheet for biomass gasification

operation blocks, material streams and the energy stream. Different conventional components were chosen from the database along with two non-conventional components for the biomass and the ash modeling. Nonconventional components were defined according to the ultimate and proximate analysis for the biomass. Table 1 gives the ultimate and proximate analysis of the different biomass feedstocks.

The process consists of different stages such as biomass decomposition (DECOMP), pyrolysis (PYRO), gasification (GASIFIER), combustion (COMB) and different separation units (cyclone and separator). MIXNCPSD stream class was used as both conventional
Figure 2 shows the flow sheet in Aspen Plus. Biomass was decomposed into its constituting elements such as $\mathrm{H}_{2} \mathrm{O}, \mathrm{ASH}, \mathrm{C}, \mathrm{H}, \mathrm{N}, \mathrm{Cl}, \mathrm{S}, \mathrm{O}$ based on the ultimate analysis. A calculator module was used to calculate the yield components of the biomass feed in the DECOMP reactor. The decomposed biomass product enters a yield reactor, simulated as a pyrolysis step in gasification. The PYRO reactor was set to operate at $500^{\circ} \mathrm{C}$ and the inert gas $\left(\mathrm{N}_{2}\right)$ was used to assist the pyrolysis step (Visconti et al., 2015). The products from the pyrolysis were separated by using a cyclone. The char produced after the pyrolysis was taken into another yield reactor (GASIFIER), simulated as a gasification reactor. 
Around 5\% of the char was combusted in RStoic reactor. The generated energy can be used as a supplement heat for the gasifier. In addition to char, gaseous product (nitrogen-free) from the pyrolysis process and the steam is added into the gasifier.

The calculation in the RGibbs gasifier was based on the restricted equilibrium with zero temperature approach for each of the reaction. The zero-approach option in RGibbs calculates the chemical equilibrium constant for the specified reaction at the reactor operating temperature. The equilibrium state of the reactor is also dependent upon the load per area of the reactor. Low load gives the state close to the equilibrium whereas higher load gives the non-equilibrium state within the reactor. High load is preferred to achieve a high conversion rate and low equipment costs. The overview of the temperature and the pressure in the different reactors is presented in Table 2 .

Table 2. Thermodynamic state of different reactor

\begin{tabular}{|l|c|c|}
\hline \multirow{2}{*}{ Reactor } & \multicolumn{2}{|c|}{ Thermodynamic state } \\
\cline { 2 - 3 } & Temperature $\left({ }^{\circ} \mathrm{C}\right)$ & Pressure (bar) \\
\hline DECOMP & 500 & 1 \\
PYRO & 500 & 1 \\
COMB & 800 & 1 \\
GASIFIER & 700 & 1 \\
\hline
\end{tabular}

Table 3 shows the lists of chemical reactions specified during this simulation study with their change in Gibbs energies respectively.

Table 3. Reactions involved in gasification (Suwatthikul et al., 2017)

\begin{tabular}{|lc|c|}
\hline Reactions & & $\begin{array}{c}\Delta \mathrm{H} \\
(\mathrm{kJ} / \mathrm{mol})\end{array}$ \\
\hline $\mathrm{C}+\mathrm{O}_{2} \rightarrow \mathrm{CO}_{2}$ & $(2)$ & -394 \\
$\mathrm{C}+0.5 \mathrm{O}_{2} \rightarrow \mathrm{CO}$ & $(3)$ & -111 \\
$\mathrm{CO}+0.5 \mathrm{O}_{2} \rightarrow \mathrm{CO}_{2}$ & $(4)$ & -283 \\
$\mathrm{C}+\mathrm{CO}_{2} \rightarrow 2 \mathrm{CO}$ & $(5)$ & +172 \\
$\mathrm{C}+\mathrm{H}_{2} \mathrm{O} \rightarrow \mathrm{CO}+\mathrm{H}_{2}$ & $(6)$ & +131 \\
$\mathrm{C}+2 \mathrm{H}_{2} \rightarrow \mathrm{CH}_{4}$ & $(7)$ & -74.8 \\
$\mathrm{CO}+\mathrm{H}_{2} \mathrm{O} \rightarrow \mathrm{H}_{2}+\mathrm{CO}_{2}$ & $(8)$ & -41.2 \\
$\mathrm{CO}+3 \mathrm{H}_{2} \rightarrow \mathrm{CH}_{4}+\mathrm{H}_{2} \mathrm{O}$ & $(9)$ & -206 \\
$\mathrm{H}_{2}+\mathrm{S} \rightarrow \mathrm{H}_{2} \mathrm{~S}$ & $(10)$ & -20.2 \\
$\mathrm{~N}_{2}+2 \mathrm{H}_{2} \rightarrow \mathrm{NH}_{3}$ & $(11)$ & -92.2 \\
$\mathrm{H}_{2}+\mathrm{Cl}_{2} \rightarrow 2 \mathrm{HCl}$ & $(12)$ & -184.6 \\
\hline
\end{tabular}

The product from the gasifier undergoes water separation to give the output product composition on a dry volume basis.

\section{Results and Discussions}

Simulation results of the wood residue feedstock were compared with the experimental results published by Fremaux et al. Figure 3 shows the composition of the different gases. Hydrogen and carbon dioxide production increases with an increase in Steam to Biomass Ratio (STBR) while the carbon monoxide production decreases with increase in STBR. Methane concentration is almost constant for the given range of STBR.

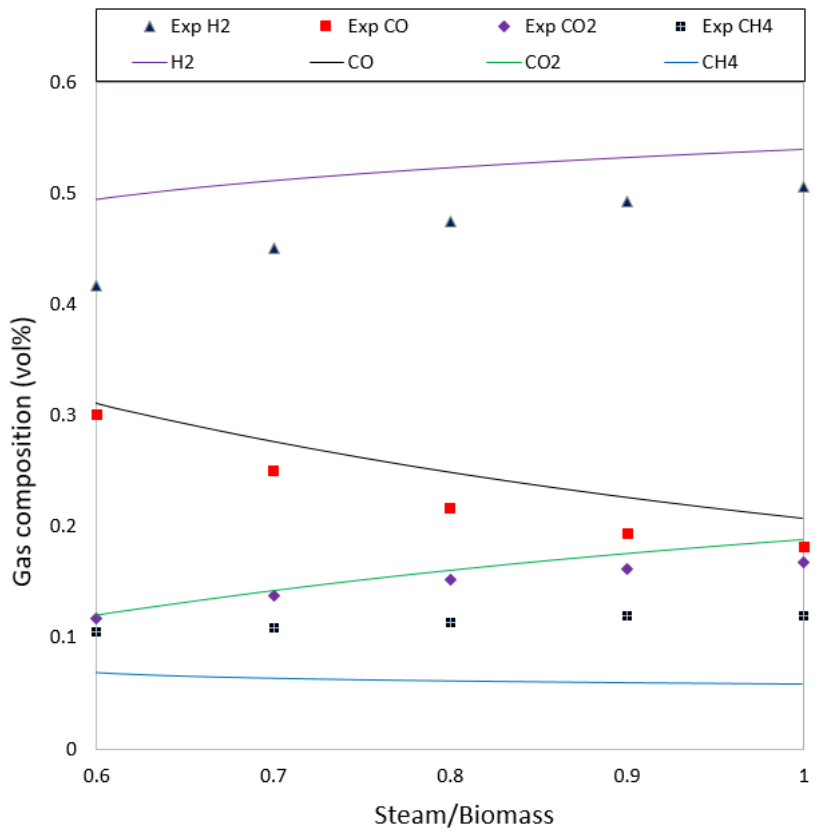

Figure 3. Gas composition for wood residue

The model predicts well the fraction of the different gas components, and there is a good agreement between experimental and computational results regarding carbon monoxide and carbon dioxide concentration. There is little difference in the hydrogen concentration, as the model doesn't represent the true phenomenological behavior of biomass gasification during the experiments.

Figure 4 shows the composition of hydrogen, carbon monoxide, carbon dioxide and methane from the simulation for different biomass. Hydrogen composition is quite similar for all the biomass feed.

Carbon monoxide concentration for wood residue, miscanthus and olive residue is similar, whereas the lowest for the pig manure. Carbon dioxide concentration for pig manure feed is $30 \%$ whereas other feed has $\mathrm{CO}_{2}$ concentration below $25 \%$. The carbon and hydrogen concentration are lowest for the pig manure. The $\mathrm{C} / \mathrm{O}$ ratio is approximately 1:1 for pig manure and 1.2:1 for the other biomass. 


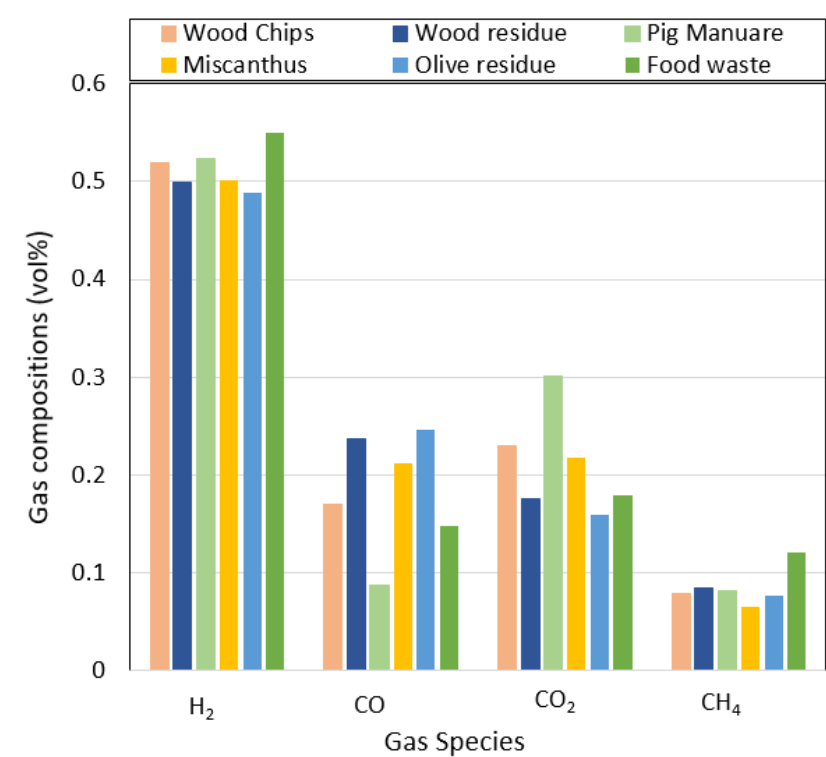

Figure 4. Gas compositions for different biomass feed $\left(700^{\circ} \mathrm{C}\right)$

The higher proportion of oxygen per carbon atom could be the reason for high $\mathrm{CO}_{2}$ and low $\mathrm{CO}$ in pig manure. The main reason for high $\mathrm{CO}_{2}$ and low $\mathrm{CO}$ is due to the high concentration of ash $(18.15 \%)$ in pig manure compared to the other biomass. Methane concentration is around $8 \%$ for all the biomass except the food waste, which is around $12 \%$.

The end use of the product gas depends upon the quality of the gas produced during gasification. One of the qualities of the product gas required for feedstock for GTL synthesis is the $\mathrm{H}_{2} / \mathrm{CO}$ ratio. $\mathrm{H}_{2} / \mathrm{CO}$ was calculated for all the biomass feed for different STBR. Figure 5 shows the $\mathrm{H}_{2} / \mathrm{CO}$ ratio for STBR in the range of $0.5-1$.

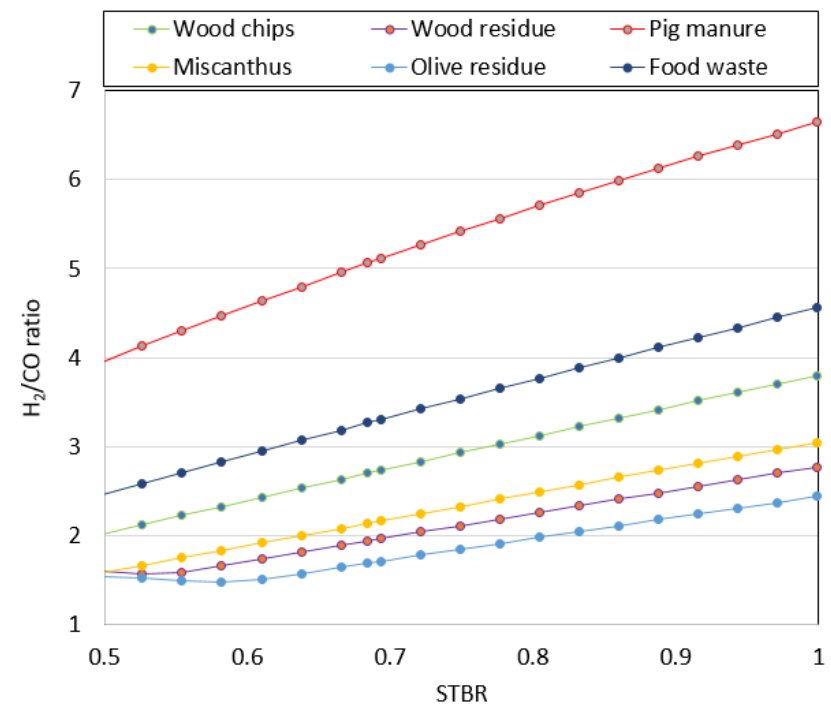

Figure 5. $\mathrm{H}_{2} / \mathrm{CO}$ ratio for different biomass feed $\left(700^{\circ} \mathrm{C}\right)$
$\mathrm{H}_{2} / \mathrm{CO}$ ratio is highest for the pig manure because of the high amounts of moisture and higher $\mathrm{C} / \mathrm{O}$ ratio compared to other biomasses. Food waste also has a higher $\mathrm{H}_{2} / \mathrm{CO}$ ratio because of its high moisture content. According to Tristantini et al., the optimal $\mathrm{H}_{2} / \mathrm{CO}$ ratio is 1.5-2.1. This is achievable from the olive residue, wood residue, miscanthus in the STBR range of 0.5 to around 0.75 . Syngas from wood chips is more suitable in FT synthesis at lower STBR. FT synthesis not only depends on the $\mathrm{H}_{2} / \mathrm{CO}$ ratio, but also temperature, catalyst used and the system. Thus, the suitable $\mathrm{H}_{2} / \mathrm{CO}$ ratio can be chosen depending upon the plant requirements.

The quality of syngas produced depends upon the reactor temperature. Figure 6 shows the variations of the product gas compositions at different temperatures.

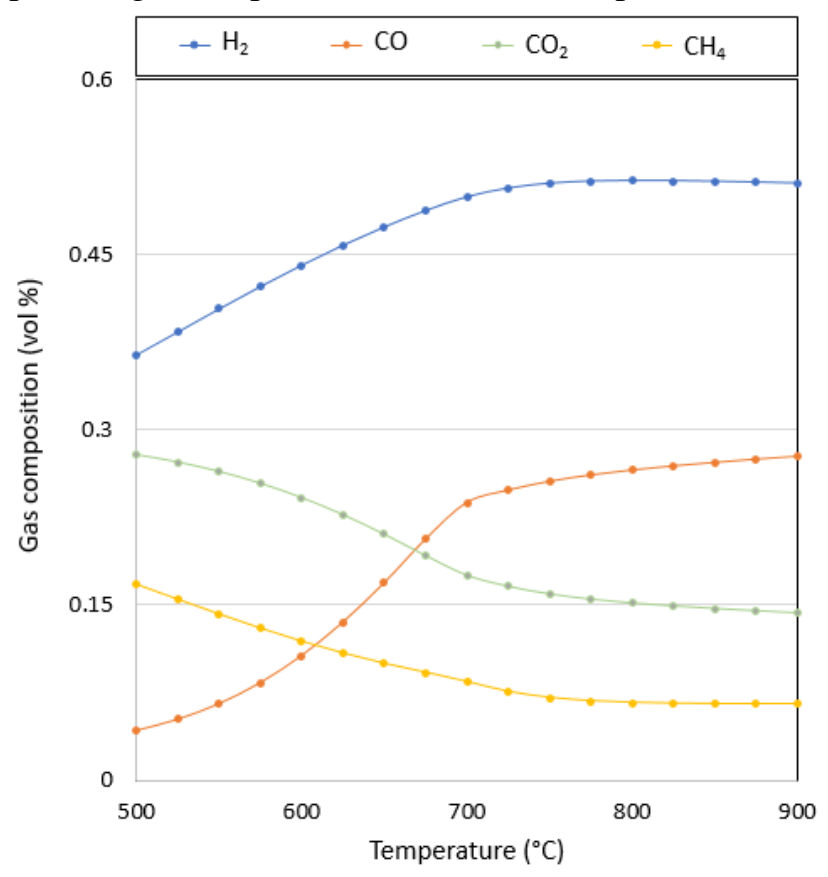

Figure 6. Gas composition for wood residue $(\mathrm{STBR}=0.6)$

Hydrogen and carbon monoxide concentration increases initially and stabilizes after $700^{\circ} \mathrm{C}$. Carbon dioxide and methane concentration decrease with increase in temperature and becomes steady after around $700^{\circ} \mathrm{C} . \mathrm{H}_{2} / \mathrm{CO}$ ratio also becomes steady at around 1.8 after $700^{\circ} \mathrm{C}$., The gas compositions were analyzed for different biomass feed. Figure 7 shows the product gas compositions for different biomass loadings. 


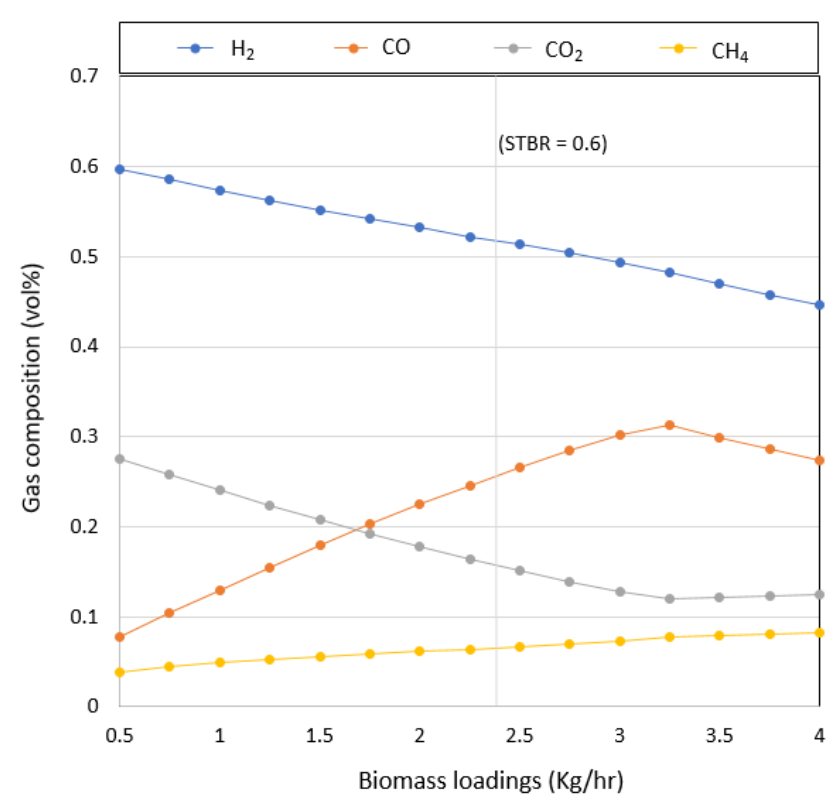

Figure 7. Gas composition for wood residue $\left(700^{\circ} \mathrm{C}\right)$

Hydrogen concentration decreases with an increase in biomass feed whereas $\mathrm{CO}$ concentration increases for biomass feed up to $3.25 \mathrm{~kg} / \mathrm{hr}$. $\mathrm{CO}_{2}$ concentration decreases and then becomes stable after biomass loading of $3.25 \mathrm{~kg} / \mathrm{hr}$. Methane concentration remains similar for all the feed rate. Increase in biomass feed favors the forward reactions (2)-(7). Further, $\mathrm{CO}_{2}$ produced during the reactions (2) and (4) reacts with carbon from the biomass to produce $\mathrm{CO}$ and the carbon partial oxidation produces $\mathrm{CO}$. Thus, $\mathrm{CO}$ concentration increases with increase in biomass feed. The $\mathrm{H}_{2}$ produced from the reaction (6) and (8) reacts with carbon (7) to produces $\mathrm{CH}_{4}$. Hence, there is a decrease in $\mathrm{H}_{2}$ concentration with an increase in biomass feed rate.

\section{Conclusions}

A steady-state Aspen Plus model was developed for biomass gasification in a fluidized bed. Simulations results were validated against the experimental data for a research scale fluidized-bed reactor. The model was used to predict the gasifier performance for different operating conditions and parameters like temperature, STBR and biomass loadings. The gas compositions were compared for different biomass feed. Hydrogen production was around $50 \%$ for all the biomasses while $\mathrm{CO}$ production varies from $8 \%$ (Pig manure) to $24.5 \%$ (Olive residue) at $700^{\circ} \mathrm{C} . \mathrm{H}_{2} / \mathrm{CO}$ ratio increases with an increase in STBR for all the biomass and $\mathrm{H}_{2} / \mathrm{CO}$ ratio was highest for pig manure and lowest for olive residue. Olive residue, wood residue and miscanthus gave the $\mathrm{H}_{2} / \mathrm{CO}$ ratio of 1.5-2.1, which are more suitable as a feedstock in Fischer-Tropsch synthesis depending upon the operating temperature, a catalyst used and other operating conditions. For wood residue, an increase in temperature increases the $\mathrm{H}_{2}$ and $\mathrm{CO}$ production, whereas $\mathrm{CO}_{2}$ and $\mathrm{CH}_{4}$ concentration decreases and becomes stable after $700^{\circ} \mathrm{C} . \mathrm{H}_{2}$ concentration increased from $46 \%$ to $54 \%$ and CO concentration decreases from $30 \%$ to $20 \%$ with an increase in STBR from 0.6 to 1 for wood residue. The experimental results may vary from the simulation modeling, as the decomposition of biomass feed doesn't represent the true phenomenological behavior during the gasification process. Suitable syngas composition for GTL synthesis can be obtained by selecting suitable biomass at desirable operating conditions of the gasifier.

\section{Acknowledgements}

The authors would like to thank the University of SouthEastern Norway (USN) for providing the necessary software for the simulation works.

\begin{tabular}{|c|c|}
\hline \\
\hline$\nabla \mathrm{H}$ - Enthalpy change & Abbreviations \\
\hline C - Carbon & O - Oxygen \\
\hline $\mathrm{H} / \mathrm{H}_{2}$ - Hydrogen & $\mathrm{CO}_{2}$ - Carbon dioxide \\
\hline FC - Fixed Carbon & $\mathrm{CH}_{4}$ - Methane \\
\hline VM - Volatile Matter & $\mathrm{H}_{2} \mathrm{O}$ - Steam (water) \\
\hline $\mathrm{N}$-Nitrogen & S - Sulphur \\
\hline $\mathrm{Cl}$ - Chlorine & kg/hr- Kilogram per hour \\
\hline \multicolumn{2}{|c|}{ GTL - Gas-to-Liquid } \\
\hline \multicolumn{2}{|c|}{ MSW - Municipal Solid Waste } \\
\hline \multicolumn{2}{|c|}{ STBR - Steam to Biomass Ratio } \\
\hline \multicolumn{2}{|c|}{$C_{x} H_{y} O_{z}$ - Biomass elemental composition } \\
\hline \multicolumn{2}{|c|}{$C_{x} H_{y}-$ Higher hydrocarbons $\left(\mathrm{C}_{2}+\right)$} \\
\hline
\end{tabular}

\section{References}

S. Begum, M. G. Rasul, D. Akbar, and N. Ramzan. Performance analysis of an integrated fixed bed gasifier model for different biomass feedstocks. Energies, 6(12): 6508-6524, 2013. doi:10.3390/en6126508

W. Doherty, A. Reynolds, and D. Kennedy. Aspen plus simulation of biomass gasification in a steam blown dual fluidised bed. 2013.

C. Franco, F. Pinto, I. Gulyurtlu, and I. Cabrita. The study of reactions influencing the biomass steam gasification process. Fuel, 82(7): 835-842, 2003. doi:10.1016/S0016-2361(02)00313-7

S. Fremaux, S. M. Beheshti, H. Ghassemi, and R. S. Markadeh. An experimental study on hydrogen-rich gas production via steam gasification of biomass in a research-scale fluidized bed. Energy Conversion and Management, 91: 427-432, 2015. doi:10.1016/ j.enconman.2014.12.048

A. Gagliano, F. Nocera, M. Bruno, and G. Cardillo. Development of an equilibrium-based model of gasification of biomass by Aspen Plus. Energy Proceedings, 111:1010-1019, 2017. doi:10.1016/ j.egypro.2017.03.264

Y. H. Kim, K. W. Jun, H. Joo, C. Han, and I. K. Song. A simulation study on gas-to-liquid (natural gas to Fisher-Tropsch synthetic fuel) process optimization. 
Chemical Engineering Journal, 155(1-2): 427-432, 2009. doi:10.1016/j.cej.2009.08.018

M. V. Kok and E. Özgür. Thermal analysis and kinetics of biomass samples. Fuel Processing Technology, 106: 739-743, 2013. doi:10.1016/j.fuproc.2012.10.010

L. Liu, Y. Huang and C. Liu. Prediction of rice husk gasification on fluidized bed gasifier based on ASPEN Plus. Bioresources, 11(1): 2744-2755, 2016.

A. T. Masiá, B. Buhre, R. P. Gupta and T. F. Wall. Characterising ash of biomass and waste. Fuel Processing Technology, 88(11-12): 1071-1081, 2007. doi:10.1016/ j.fuproc.2007.06.011

P. McKendry. Energy production from biomass (part 1): overview of biomass. Bioresource technology, 83(1): 3746, 2002. doi:10.1016/S0960-8524(01)00118-3

M. B. Nikoo and N. Mahinpey. Simulation of biomass gasification in fluidized bed reactor using ASPEN PLUS. Biomass and Bioenergy 32(12): 1245-1254, 2008. doi:10.1016/j.biombioe.2008.02.020

T. Riedel et al., Comparative study of Fischer-Tropsch synthesis with $\mathrm{H} 2 / \mathrm{CO}$ and $\mathrm{H} 2 / \mathrm{CO} 2$ syngas using $\mathrm{Fe}$-and Co-based catalysts. Applied Catalysis A: General, 186(12): 201-213, 1999. doi: 10.1016/S0926-860X(99)00173-8

A. Suwatthikul, S. Limprachaya, P. Kittisupakorn and I. M. Mujtaba. Simulation of steam gasification in a fluidized bed reactor with energy self-sufficient condition. Ener gies, 10(3): 314, 2017. doi:10.3390/en10030314

R. Thapa and B. Halvorsen. Stepwise analysis of reactions and reacting flow in a dual fluidized bed gasification reactor. Adv. Fluid Mech, 82(12): 37-48, 2014.

D. Tristantini, S. Lögdberg, B. Gevert, Ø. Borg and A. Holmen. The effect of synthesis gas composition on the Fischer-Tropsch synthesis over $\mathrm{Co} / \gamma-\mathrm{Al} 2 \mathrm{O} 3$ and $\mathrm{Co}-\mathrm{Re} / \gamma-$ Al2O3 catalysts. Fuel Processing Technology, 88(7): 643-649, 2007. doi:10.1016/j.fuproc.2007.01.012

A. Visconti, M. Miccio and D. Juchelková. An aspen plus tool for simulation of lignocellulosic biomass pyrolysis via equilibrium and ranking of the main process variables." International Journal of Mathematical Models and Methods in Applied Sciences, 9: 71-86, 2015.

$\mathrm{X}$. Xiao et al., Catalytic steam gasification of biomass in fluidized bed at low temperature: conversion from livestock manure compost to hydrogen-rich syngas. Biomass and Bioenergy, 34(10): 1505-1512, 2010. doi:10.1016/ j.biombioe.2010.05.001 